\title{
VIOLENCIA SOCIAL EN LA PRIMERA MITAD DEL SIGLO XIX MEXICANO: EL CASO DE LAS HUASTECAS ${ }^{1}$
}

\author{
POR
}

\author{
ANTONIO ESCOBAR OHMSTEDE
}

CIESAS, D.F.

\begin{abstract}
El presente artículo observa varias fases de la violencia rural que se dio en un espacio social del noreste de México denominado las Huastecas en la primera mitad del siglo XIX. Se abordan los movimientos sociales atendiendo tanto a sus causas, como a los actores y generadores de la violencia colectiva. Al respecto se analiza el papel de los indígenas, mulatos y mestizos que vivian en los pueblos y en las propiedades privadas y los mecanismos y alianzas que se dieron entre los diversos grupos de poder regional.
\end{abstract}

Palabras Clave: Rebelión, sectores populares, Constitución, México, Huastecas.

La historiografía mexicanista ha abordado la violencia como el efecto de las transformaciones inducidas por la «modernidad liberal» decimonónica, reflejadas en las modificaciones que paulatinamente se dieron en la tenencia de la tierra, en las relaciones socio-políticas, en la apropiación, manejo y control de los recursos naturales o en el incremento de una agricultura con tintes «capitalistas», poniendo énfasis en los cambios propuestos o impuestos por un sector socio-étnico («blanco-mestizos») a los pueblos de indios o campesinos. Se han analizado a los movimientos sociales que se dieron en las zonas rurales como el resultado del choque entre dos sistemas sociales, culturales, políticos y productivos que entraron en contradicción debido a visiones diferentes del

1 Una versión de este trabajo se elaboró en un semestre sabático (marzo-septiembre 2008) en El Colegio de San Luis, A.C., apoyado y financiado por el Consejo Nacional de Ciencia y Tecnología (CONACyT). Asimismo, agradezco los comentarios y sugerencias de la Dra. Marta Irurozqui, que en mucho mejoraron la presente versión. 
mundo ${ }^{2}$. Este planteamiento puede ser válido hasta cierto punto, pero existen una serie de relaciones sociales, culturales, económicas y políticas más complejas que la reproducción de un tipo de sistema dualista, esto es, entre los indígenas y los que no los son, entre los que poseen riqueza y los que carecen de ella, entre tradición y modernidad, o entre campo y ciudad. Pocos estudios regionales o de caso han explicado la complementariedad e inclusive la dependencia (relación simbiótica) de lo que parecen dos o más sistemas antagónicos, que no forzosamente buscan la eliminación de uno o de varios de los contrincantes, sino que en muchos casos se complementan.

El presente artículo se encuentra enmarcado en un espacio social denominado las Huastecas, que se sitúa al noreste de México ${ }^{3}$. En él se puede caracterizar a la violencia como el conjunto de acciones más o menos efímeras, con objetivos limitados, que en muchos casos fueron incluidas en manifestaciones activas políticas regionales o nacionales y que involucraron a grupos multiétnicos relativamente pequeños de los ámbitos locales en que influyeron, sea por su difusión o su movilidad en espacios regionales. La manera en que se desarrolla la violencia no solamente depende del momento en que se da, sino en entender sus antes y después. Es allí donde pueden converger diversas expresiones organizadas, atomizadas y diferentes, cuyos hilos conductores no se reducen a uno solo sino a una conjunción de varios, cada una con su justificación correspondiente, con independencia de que sólo uno específico actúe de «detonante» de una situación dada ${ }^{4}$. Algunos rebeldes esgrimieron motivos agrarios 5 , mientras otros los vincularon a la actividad desarrollada por las tropas de ocupación extranjeras ${ }^{6}$. Los impuestos civiles y eclesiásticos también fueron motivo de la protesta de los habitantes de los pueblos, al igual que la permanencia de monopolios coloniales, como el del estanco del tabaco en la Sierra Gorda y en la Huasteca potosina que ocasionó que los propietarios particulares «blanco-mestizos» e indígenas se opusieran a tal medida ${ }^{7}$. Aspectos

2 Véase Reina, 1988: 517-541; 1995: 53-76. Knight, 1995: 13-52. McFarlane, 1998: 7-38. Tutino, 2000: 125-152. Mallon, 2003. Jacobsen y Díez Hurtado, 2002: 59-67.

3 Para una breve descripción geográfica, poblacional y cultural de las Huastecas para el período colonial y el decimonónico, véase Escobar Ohmstede, 1998: 27-54. Monroy y Calvi1lo, 1997: 21-39. Herrera, 1999: 13-69. Blázquez, 2000: 11-94.

4 Sobre conflictos, aunque no todos violentos por los recursos naturales, Birrichaga, 2005: 255-282.

5 Tutino, 1986: 249-258; 1988, vol. I: 108-112. Para el caso de Oaxaca-Guerrero, Hart, 1988, vol. I: 225-241. Guardino, 1996. Reina, 1988, vol. I: 258. Mallon, 2003.

6 Tutino, 1986: 248-258. Ducey, 2004.

7 Archivo Histórico de la Secretaría de la Defensa Nacional, México (AHSDN), exp. XI/481.3/1612, fs. 36-37; Corbett, 2002: 235-268. Escobar Ohmstede, 2006: 81-123. 
políticos internos, como las elecciones de los miembros de los ayuntamientos, o relacionados con el control de las redes económicas-comerciales provocaron divisiones y enfrentamientos entre los grupos de poder regionales y sus clientelas. Los orígenes y causas de la violencia muestran, así, muchos colores, intensidades y niveles, además de desenvolverse en variadas regiones. En ocasiones los diversos participantes ni reconocen de manera inmediata los motivos de una movilización más allá de los más evidentes, ni están al corriente de un posible objetivo común a mediano plazo sólo manejado por los líderes merced a su uso de múltiples redes cotidianas de poder. De ahí que éstos enarbolaran soluciones a problemas que no afectaban directamente a los habitantes rurales, como podría ser los cambios en los tipos y formas de gobierno ${ }^{8}$.

En el marco de las luchas internas por el control de la nación y de las regiones se desarrollaron diversos niveles de violencia durante la primera mitad del siglo XIX en las actuales Huastecas hidalguense, potosina y veracruzana. Éstos estuvieron relacionados con intereses opuestos a los grupos de poder regional y se reflejaron en la hegemonía del aparato político (ayuntamientos), en el acceso y control sobre los recursos naturales o en las redes comerciales, siendo sus detonantes inmediatos la solicitud de reducción de las rentas o la petición de tierras. Fueron expresión de los conflictos para acceder al poder por parte de los diversos grupos «nacionales».

Antes de continuar, debo realizar cuatro aclaraciones para entender la naturaleza de los conflictos desarrollados en el área. Primera, si bien el telón de fondo es un espacio social construido históricamente, las fronteras políticoadministrativas, religiosas, fiscales y jurisdiccionales fueron poco nítidas, por lo que los diversos actores sociales las atravesaron sin saber con exactitud en qué jurisdicción se encontraban, existiendo, así, un cruce de identidades locales y regionales. Por lo anterior, en varias ocasiones mencionaremos al Valle del Maíz y Rioverde (San Luis Potosí) como lugares de referencia de ciertos acontecimientos y procesos, aun cuando ambos no se podrían considerar ni políticamente ni geográficamente como parte de las Huastecas, pese a que, en el caso de la villa del Valle del Maíz, ésta perteneció a la jurisdicción huasteca de Villa de Valles hasta 1821.

Segunda, la composición de la población era heterogénea. En las localidades de la Huasteca veracruzana existían nahuas y otomíes en la sierra, mientras que en una parte de la planicie costera se encontraban poblaciones mulatas

8 Véase por ejemplo, los casos de Chile, Cuba, Perú, República Dominicana en Escobar Ohmstede y Falcón, 2002. Para el caso de México Falcón (coord.), 2005. Ducey, 2002: 111-136; 2004. Para Bolivia, Irurozqui, 1997: 44-49. Respecto a Colombia, König, 2002: 207-224. 
asentadas en algunas propiedades privadas y pueblos de indios. Asimismo, hacia el norte de Tuxpan, casi llegando a Pánuco (Veracruz), las misiones franciscanas habían logrado congregar y reducir a pames, quienes, según los informes misionales, se habían ido suicidando para evitar estar en "policía»" . Sin embargo, debido al poblamiento que se dio desde el contacto con los españoles y al tipo de ocupación de la tierra, era una zona más mestizo-mulata que india. Conforme avanzamos de la costa a la sierra encontramos población nahua en Chicontepec y su jurisdicción (Veracruz). Cruzando la sierra, en lo que hoy correspondería a la Huasteca hidalguense, las jurisdicciones de Huejutla-Yahualica contenían una importante población de nahuas y otomíes que vivían en los pueblos, barrios, haciendas y ranchos, junto con mulatos, mestizos y criollos, muchos de ellos asentados en las cabeceras y en las haciendas. Desde Huejutla hacia el norte encontramos una Huasteca potosina con nahuas, teenek y pames. Allí las haciendas, ranchos, pueblos de indios, barrios, así como las misiones-pueblo contenían una población diversa. Sin embargo, los mulatos y pardos jugaron un papel preponderante como milicianos, como ocurrió en Tuxpan (Veracruz) y en algunas haciendas de Huejutla (Huasteca hidalguense) y de Villa de Valles. Al respecto sobresalió el pueblo de San Antonio y sus rancherías (Huasteca potosina), cuya población se componía del 79\% de mulatos y algunos españoles, asentándose los indígenas en algunos de sus barrios.

Tercera, la etnicidad continuó siendo negociable en el período republicano como ya lo había sido durante el colonial. Los indios podían librarse de su «etiqueta» mediante la movilidad social o geográfica y perderse dentro del grupo de población étnicamente no diferenciado ${ }^{10}$. Y, cuarta, en el ámbito político hubo un conflicto de competencia, gestión y jurisdicción entre poderes locales cuando el ayuntamiento gaditano y su heredero intentaron sobreponerse a una parte de las autoridades étnicas, «eliminando» de esta manera a la cabeza piramidal del gobierno indio: el gobernador, quien representaba el mayor rango dentro de la jerarquía. Sin embargo, los pueblos de indios mantuvieron su estructura, ya no en las cabeceras sino en los

\footnotetext{
9 Escobar Ohmstede y Fagoaga, XXV (México, 2004): 219-256.

10 En 1825 el alcalde del ayuntamiento de Tampamolón (Huasteca potosina) recibía una llamada de atención del gobernador potosino, al comentar «que con sorpresa he visto en la citada noticia que se hace distinción de ciudadanos naturales y otros a quienes se llama españoles y castas (...) he mandado a borrar en la expresada noticia las atadas expresiones y espero que haga V.S. otro tanto en la copia que haya dejado». Archivo Histórico del Estado de San Luis Potosí, San Luis Potosí (AHESLP), Secretaría General de Gobierno, leg. 1825, exp. 1. Véase también Noticias estadísticas [del arzobispado de México]. 1845, Archivo General de la Nación, México (AGN), Bienes Nacionales, vol. 369, exp. 40.
} 
pueblos-sujetos o barrios, siendo ahora el alcalde el representante del territorio indígena ${ }^{11}$.

\section{¿Violencia ÉtNiCA O DE ClaSe? En los PRIMEROS AÑos DECIMONÓNICOS}

Durante los primeros momentos de la insurgencia en las Huastecas (1810), los gobiernos indios fueron un actor político de primer nivel y apoyaron de manera indistinta a insurgentes y a realistas ${ }^{12}$. En los pueblos-cabeceras huastecos en que existió un mayor control sobre la población, los indígenas optaron por el gobierno español. Por ejemplo, el teniente general de Yahualica (Huasteca hidalguense) informaba a las autoridades virreinales del «entusiasmo de los nobles indios» en el plan de defensa de Huejutla ${ }^{13}$, a pesar del «pánico» que representaba para el subdelegado de Huejutla el levantamiento de Tamazunchale y Tancanhuitz (Huasteca potosina) ${ }^{14}$. El temor se debía a la concentración indígena en los alrededores de Huejutla, ya producida en Tamazunchale antes de ser atacado por las fuerzas insurgentes compuestas básicamente de indígenas. A diferencia de lo acontecido en Huejutla, en Chicontepec (Huasteca veracruzana), el subdelegado avisaba desde mayo de 1811, que gracias a los informes del gobernador indio de Zontecomatlán, se tenía noticias de «partidas» importantes de rebeldes. En ese mismo mes, los insurgentes de Tianguistengo solicitaban a los gobernadores indios de Chicontepec, Huayacocotla y Zontecomatlán que apresaran a las autoridades españoles y a todos aquellos que se opusiesen «a la Nación Americana». La respuesta de los gobernadores fue inmediata. Mandaron mensajeros a los alcaldes de Ixhuatlán, Xochioloco, Huayacocotla e Ilamatlán (Veracruz) para que cuidaran los caminos y capturasen al subdelegado que había huido de la cabecera. La tensión duró menos de un mes cuando se dio el aviso de la captura de los «cabecillas mestizos», más no de los miembros del gobierno indígena, a quienes sólo se iba a mantener bajo una rigurosa vigilancia por temor a que se levantaran de nuevo. Aun con la aprehensión de los «líderes» rebeldes, la situación continuó

11 Ducey, 2002: 111-136. Escobar Ohmstede, 1997: 294-316. Asimismo, para observar otras acciones, véase varios de los trabajos que se encuentran en Ortiz y Serrano (coords.), 2007. Para una visión general sobre el constitucionalismo gaditano, Quijada, LXVIII/242 (Madrid, 2008): 15-38.

12 Escobar Ohmstede, 2002: 217-235. Ducey, 2004: 60-93. Rangel, 2006: 47-80.

13 AGN, Historia, t. 105, exp. 55, f. 203. En Matehuala (San Luis Potosí) rondaba una «división de indios» de Nola, Tula y Palma bajo el mando del «indio» Bernardo Gómez de Lara, alias el Guacal. AGN, Historia, t. 103, exp. 17, f. 73, así como Rangel, 2006: 57.

14 Sobre el caso de la Huasteca potosina en la insurgencia, Rangel, 2006: 49-64. 
tensa, ya que el comandante de las milicias eligió una nueva república. Los indígenas se opusieron por considerar que sus miembros eran individuos ajenos a los intereses del pueblo, pero muy capaces de seguir las órdenes del comandante. El teniente que condujo a los prisioneros de Chicontepec a Tuxpan dijo en su informe militar que tuvo que castigar a dos indios con la picota, que uno de ellos comentó «como amenazando a la tropa: han prendido al gobernador pues hay verán las resultas: y el otro por haber amenazado con la muerte a uno de razón; diciéndole: que él y los demás de su clase eran la causa de la prisión de los indios» ${ }^{15}$. Sin duda, este tipo de comentarios mostraría el «odio racial» que podría haberse dado entre los diversos contrincantes, aunque el comentario del teniente pudo haber sido una autojustificación por haber castigado tan severamente a dos indígenas.

Las fuerzas combatientes se habían mantenido desde mediados de 1812 en sus respectivas posiciones. Ello cambió a principios de 1813, cuando los pueblos de Tantima, Tuxpan y Santa Catarina Chontla se vieron rodeados por insurgentes ${ }^{16}$. A pesar de los niveles que alcanzó la violencia durante los primeros años de la insurgencia, en las Huastecas el régimen constitucional gaditano se constituyó desde agosto-septiembre de 1813, dependiendo de la presencia de fuerzas realistas en aquellos pueblos donde se realizaron comicios ${ }^{17}$. A la restauración de la Constitución casi siete años después, la situación no había mejorado sustancialmente. Por ejemplo, en septiembre de 1820 el subdelegado interino de Tancanhuitz (Huasteca potosina) comentó respecto a los gobiernos indios que «unos se han suprimido y otros no; es materia que no me atrevo a resolver: en este pueblo esta suprimido para el alcalde [constitucional], y me

15 AGN, Historia, vol. 411, s.n.e., fs. 136-137r.; AGN, Infidencias, t. 17, exp. 9, ff. 234-253. En 1815, las autoridades virreinales decidieron mandar al gobernador indio de Chicontepec a las Islas Marianas, dejando en libertad a los demás inculpados. AGN, Infidencias, t. 17, exp. 11.

16 Se decía que los insurgentes que habían sitiado los pueblos alcanzaban los dos mil hombres. AGN, Operaciones de guerra, t. 687, f. 3. En 1814, la hacienda de San Isidro fue quemada, no sólo la casa, sino también los corrales y las siembras. AGN, Operaciones de guerra, t. 976, f. 216. En 1816, las haciendas que se ubicaban cercanas al pueblo de Ozuluama fueron atacadas e incendiadas. AGN, Operaciones de guerra, t. 687. Asimismo, la hacienda de San Pedro Vaquerías, ubicada en Huayacocotla (Veracruz), causante de uno de los tumultos del siglo XVIII, fue incendiada y saqueada por los insurgentes. En 1819, los diversos propietarios privados y apoderados informaban de las pérdidas que habían sufrido durante la estancia del «español-insurgente» Xavier Mina en Valle del Maíz (San Luis Potosí).

17 Un ejemplo interesante es el comentario del intendente-corregidor de San Luis Potosí, quien en mayo de 1813 avisaba que, debido a que en ese momento se encontraban libres de «rebeldes» diez o doce pueblos de la jurisdicción de Villa de Valles, saldría a ese lugar para realizar las elecciones parroquiales y de partido. AHESLP, Intendencia, leg. 1813 (1), exp. 12. 
parece que puede haber algún trastorno, pues los indios no están en estado de darles solturas ${ }^{18}$. En varios casos los ayuntamientos se enfrentaron a problemas heredados por los conflictos entre las cabeceras indias y los pueblos-sujetos. Los ayuntamientos de las Huastecas comenzaron a exigir los servicios que los sujetos antes prestaban a la cabecera india, negándose éstos a ello de una manera constante con el argumento de que en nada les beneficiaba, o sencillamente replegándose a los montes y serranías. Cruzando la barrera cronológica de la independencia, se observará cómo incidieron en el proceso del cambio social las transformaciones institucionales, cómo fueron cambiando el concepto de gobierno y gobernabilidad, las relaciones entre los gobiernos locales y la organización indígena, qué readecuaciones experimentaron los derechos territoriales y qué negociaron y aceptaron los pueblos de indios en sus alianzas con los grupos de poder de las Huastecas.

\title{
ViOLENCIA EN EL MÉXICO REPUBLICANO. UNA PRIMERA FASE EN LA VIOLENCIA
}

\begin{abstract}
El país está en un estado que demanda serios cuidados para evitar que se realice una revolución de castas en toda la Huasteca; la que sería desastrosa, como difícil de apagar una vez encendida, pues los naturales con el convencimiento del terreno pueden obrar contra las tropas que los persiguen [...] el ruido sordo que anuncia una tempestad fácil de conjurar al principio para que no se repita acaso en mayor escala la larga guerra que sostuvo el cabecilla Olarte en los propios terrenos ${ }^{19}$.
\end{abstract}

El comentario se hacía en medio de la aguda crisis nacional e internacional y resultaba profético de alguna manera, sobre todo por los antecedentes que se tenían desde diciembre de 1845, en que el prefecto de Tuxpan y Chicontepec (Huasteca veracruzana), Anastasio María Llorente, informaba al ministro de guerra que el teniente coronel Luciano Velázquez causaba desórdenes en el pueblo de San Nicolás al estar tratando de recolectar dinero. Una denuncia semejante se realizó sobre los alcaldes indígenas de la Huasteca potosina.

El antecedente más inmediato, dejando de lado las guerras insurgentes, de los conflictos que se desarrollaron a fines de los cuarenta en las Huastecas fue cuando las autoridades potosinas negaron la autorización a los indígenas de Tamazunchale (San Luis Potosí) para buscar por medio de apoderados los títulos de sus tierras localizados en el Archivo General de la Nación en la Ciudad de México. Además se encontraba la solicitud de que los indios deseaban se-

18 AHESLP, Intendencia, leg. 1821 (1), exp. 2.

19 AHSDN, exp. XI/481.3/2153, f. 106. 
guir nombrado a sus propias autoridades, quienes iban a poder reactivar los «auxilios» necesarios para reclamar y obtener lo que les correspondía desde «tiempo inmemorial» ${ }^{20}$. Es importante considerar que este argumento buscaba la legitimación de dichas autoridades étnicas (gobernadores, mayordomos, capitanes, caudillos y contaban con concejos de ancianos), ya que los seguían eligiendo para asuntos internos y, en ocasiones, externos, al menos hasta fines del siglo XIX. En una comunicación al presidente de la República de diciembre de 1845, denunciaban los contubernios de las autoridades locales para quitarles sus terrenos. Lo interesante del momento en que se escribe la carta es que en las mismas fechas varios pueblos de la Huasteca veracruzana, encabezados por sus autoridades étnicas, estaban realizando colectas para pagar a los apoderados y la búsqueda de sus títulos de propiedad en el Archivo General de la Nación en la ciudad de México. Es más, los argumentos esgrimidos por los indígenas principales de Tamazunchale, sobre el papel de juez y las autoridades son similares a los que se presentaron en la planicie costera veracruzana. En ambas Huastecas se pretendieron recuperar los terrenos de los pueblos de manera violenta en 1848. Sin embargo, el nivel que tuvo su ejercicio no es comparable en cada caso, ya que en la parte veracruzana alcanzó niveles de «odio» verbal y físico hacia las autoridades mestizas.

El problema aparente para las autoridades era el de tierras, ya que desde mediados de 1845 los indígenas de Ozuluama (Huasteca veracruzana) reunían mil pesos para obtener títulos de propiedad sobre las mismas. El descontento se extendía a los pueblos, incluyendo la zona de Tampico, donde se había difundido que las tierras eran comunes y que, por lo tanto, no se pagara su arrendamiento ${ }^{21}$. La recolección del dinero no sólo se había dado en Ozuluama, sino en otros pueblos huastecos que habían iniciado la búsqueda de títulos de propiedad territorial, ya que la posesión sí la tenían. En marzo de 1846 los jueces de paz de Santa María Ixcatepec, pueblo situado en las faldas de la llamada sierra de San Juan entre Tantoyuca y Amatlán, solicitaron a cada vecino dos pesos para recaudar los doscientos que exigía el proceso judicial que estaban llevando en Ozuluama. Pareciese, así, que las autoridades indígenas no sólo

20 En 1845, el juez de paz de Aquismón (Huasteca potosina) realizó una colecta entre los vecinos de la localidad para enfrentar un litigio con los propietarios de la hacienda de Santa Isabel, quienes se habían apropiado de unos terrenos pertenecientes a los ejidos de la Villa. AHESLP, Secretaría General de Gobierno, leg. 1845.33.

21 El municipio de Ozuluama estaba conformado por cinco haciendas, en las cuales arrendaban tierras los habitantes del pueblo. Tierras que en el siglo XVIII aparecían como propiedades privadas. El Archivo General de la Nación mandó un oficio el 31 de mayo de 1846 en el que se dice que no se reprodujeron las copias sobre derechos de tierras por no pagar el dinero requerido solicitado a Luciano Velázquez. AHSDN, exp. XI/481.3/2931, f. 10. 
realizaban la colecta, sino que dirigían un movimiento no violento de recuperación de tierras ${ }^{22}$.

La búsqueda de los títulos de los pueblos ocasionó un temor de parte de los propietarios privados de las Huastecas veracruzana y potosina, quienes veían la posibilidad de perder tierras «legalmente usurpadas». El contraataque de los propietarios, al menos en el caso veracruzano, se produjo mediante la solicitud de un juicio contra el «principal anarquista de la zona» (Luciano Velázquez), quien había «engañado» a los arrendatarios indígenas diciéndoles que «las tierras eran suyas desde antes de la conquista». Asimismo, pidieron el cumplimiento de las leyes que protegían la propiedad, el apoyo de tropas federales, no de milicias, y una exención de impuestos para los que no hubieran podido cobrar las rentas ${ }^{23}$.

Un año después se levantaron los pueblos de Amatlán, San Antonio, Tepecintla y Tancoco del partido de Tuxpan (Veracruz). En este momento una parte de la estructura política indígena lideró el movimiento. Estaba representada por los alcaldes indígenas de los pueblos-sujetos, quienes habían apoyado a los jueces de paz (funcionarios que en algunas localidades representaban a los ayuntamientos y que en muchos casos eran indígenas) en la recolección del dinero para la localización de los títulos. Tiempo después los indígenas argumentaron que la reclamación en torno a las tierras había sido el «[...] fundamento de la última revolución que fue indispensable hacer porque la inaudita persecución que sufríamos nos abordó hasta el desesperado extremo de tener que apelar a la fuerza física para salvarnos del inhumano proceder con que se nos trataba» ${ }^{24}$.

Los rebeldes de los pueblos sublevados se movieron hacia el norte con la finalidad de llegar a Ozuluama. El pueblo fue tomado por setecientos indígenas teenek y nahuas, quienes dieron muerte al juez de primera instancia y a un miembro de la prominente familia Jáuregui. La presencia del ejército no pacificó la zona, sino que después de la ocupación de Ozuluama y de la quema de los tribunales y muerte del juez, los indios se dispersaron, manifestando de esta manera su rechazo a la justicia de los «blancos», percibida tiránica y para nada «justa».

22 El jefe político del departamento de Tampico mencionó que los alcaldes de las rancherías habían sido quienes levantaron en armas a los habitantes. AGN, Gobernación, caja 357, exp. 2, s/s, fs. 129-130; AGN, Gobernación, caja 342, exp. 7, s/s, fs. 69-70.

23 AHSDN, exp. XI/481.3/2153. El poco valor que los propietarios le daban a los títulos indígenas queda manifiesto cuando meses después se criticó a Velázquez por sacarle dinero a los indios por "esos papeluchos que los cándidos indios reciben con música».

24 AGN, Gobernación, caja 383, exp. 13, s/s. 
Cuando volvió la paz a la zona, se iniciaron las investigaciones para saber las causas del levantamiento y castigar a los posibles culpables. Durante las averiguaciones se supo que los indígenas habían ganado puestos de regidores en el ayuntamiento de Ozuluama y exigían el respeto de las elecciones. Las autoridades del distrito las consideraban ilegítimas, porque algunos habían participado en la recuperación de títulos de propiedad y habían faltado el respeto a las autoridades municipales salientes ${ }^{25}$. Sin embargo, la polémica parecía aludir a una renegociación de los derechos territoriales y de uso (tierras, montes, leña, pastoreo, agua) que mantenían con los hacendados. En este aspecto podemos dividir en dos partes a los pueblos, aquellos que querían tierras y los que solicitaban menos rentas. En el primer caso estaban los pueblos de San Nicolás, Amatlán, San Antonio, Tepezintla y Tancoco (Huasteca veracruzana), mientras que en el segundo se encontraban los pobladores de Ozuluama.

\section{UNA SEGUNDA FASE EN LA VIOLENCIA}

Los inicios de las protestas indígenas se centraron en el aspecto material, esto es, en la reducción de las rentas de arrendamiento y en la recuperación o delimitación de sus tierras frente al intento de expansión de las haciendas ganaderas. Sin embargo, el aspecto político también estaba latente, al menos entre la elite indígena, sector que pretendía ascender en la pirámide socioeconómica y política mediante la ocupación de los puestos ganados en el ayuntamiento. Ello nos permite entender cómo en muchos de los pueblos levantados existieron divisiones, en el sentido de que no toda la población apoyaba un movimiento violento.

Pronto aparecería un nuevo detonante de la violencia, en este caso la guerra e invasión de los Estados Unidos. En marzo de 1847 se recibían las noticias de la ocupación de Tuxpan por las fuerzas norteamericanas y su posible avance desde Tampico hacia San Luis Potosí. Ante ello urgía a los diversos prefectos y subprefectos que levantaran fuerzas armadas y fortificaciones, así como que los escuadrones de caballería recorrieran los caminos entre Valles y Ciudad del Maíz (Huasteca potosina), con el fin de evitar el contrabando y el comercio realizados por algunos «vecinos» con los norteamericanos ${ }^{26}$. El prefec-

25 En abril de 1846 el prefecto de Ozuluama comentó al Ministro de Relaciones que los indígenas habían tenido tanta participación en las elecciones del ayuntamiento que salieron regidores entre ellos. AGN, Gobernación, caja 342, exp. 7, s/s. fs. 70-73.

26 AHESLP, Secretaría General de Gobierno, legs. 1847.13, 1847.15. Sobre el contraban- 
to de Tancanhuitz informaba de los grandes esfuerzos que se realizaban para enrolar soldados tanto para combatir a los invasores, como para detener el «escandaloso» contrabando que se hacía con poblaciones ocupadas por éstos. A la par, frente a lo que parecía la incapacidad del gobierno federal de enfrentarse con éxito a los norteamericanos de Tampico y Tuxpan, el ayuntamiento de Tuxpan, el prefecto de Tampico de Veracruz, el representante de Huejutla, el subprefecto de Tantoyuca, el comisionado de Yahualica, así como otras personas notables crearon una «Junta Popular de la Villa de Tamiahua». Su objetivo era obtener armas y adiestrar a los vecinos en la defensa del territorio. Asimismo, invitaron al prefecto político de Villa de Valles a asistir a una reunión de coalición entre los departamentos de Huejutla, Tampico, Tancanhuitz, Tuxpan y Papantla que se celebraría en Tantima ${ }^{27}$.

En noviembre de 1847 estalló la rebelión en el departamento de Tampico. La agitación, originada nuevamente en el pueblo de Ozuluama, parecía una «lucha de clases», esto es, entre los poseedores y los que nada poseían. Los sublevados atacaron las casas de los miembros del ayuntamiento, de los hacendados y de la autoridad judicial. Los líderes del movimiento no eran en esta ocasión los miembros de la estructura política india. El comandante militar de Huejutla informaba que la rebelión estaba compuesta por indios, negros, blancos y mulatos, así como por arrendatarios de las haciendas que rodeaban el pueblo de Ozuluama. Su queja principal era la reducción de rentas y la eliminación de los servicios personales como domésticos ${ }^{28}$.

Los rebeldes fueron violentamente atacados, aun cuando el comandante de Barlovento desmentía una noticia del 2 de diciembre de 1847 del periódico $E l$ Monitor Republicano sobre la existencia de una «guerra de castas» en las Huastecas. A su entender, la violencia no se había dado, pero las injusticias de «una docena de familias que han engordado con el sudor del desgraciado que nace y muere sin apercibirse de su sagrada misión en este pícaro mundo [...]», la atizaba ${ }^{29}$. El comandante estaba mal informado o intentaba ocultar los acontecimientos que se sucedían en la zona, ya que la noticia de la sublevación se conoció tan deprisa que días después acudían miembros de los pueblos de

do, no solamente durante la invasión norteamericana, sino durante la primera mitad del siglo XIX en el sur de la Huasteca potosina, Corbett, 2002: 235-268.

27 El documento se encuentra en Monroy y Calvillo, 1997: 130, también en AHESLP, Secretaría General de Gobierno, leg. 1847.18.

28 Las agresiones físicas, los servicios personales y los excesivos cobros de renta habían sido las causas de por qué los habitantes de San Nicolás y de las rancherías de Tantima se sublevaron. AGN, Gobernación, caja 341, exp. 7, s/s, fs. 11-14.

29 AHSDN, exp. XI/481.3/2153, f. 70 . 
Amatlán y San Nicolás. Las autoridades militares consideraron que los indígenas se habían sublevado por el apoyo dado por el ejército norteamericano para dividir y debilitar las fuerzas mexicanas, ya que diversos movimientos rurales surgieron en el país al mismo tiempo. El eje del movimiento pasó de Ozuluama a los pueblos de San Nicolás y Amatlán, debido principalmente a un convenio firmado entre los sublevados y el comandante militar Luis G. Vives. En el acta se ordenaba la entrega de los títulos legales o ilegales de los hacendados para cotejarlos, la interrupción del pago de arrendamiento, ya que les habían aumentado las rentas y expulsado de las tierras, y la suspensión de las contribuciones hasta que se solucionaran los problemas, lo cual fue ratificado por el gobierno el 12 de enero de 1848. En contraste, el caso de los rebeldes de San Nicolás, a diferencia del de Ozuluama, parecía no tener tan fácil solución. La sublevación de estos pueblos se debía a la negativa de pagar el arrendamiento de unas tierras de la hacienda de San Benito porque ésta se las había arrebatado previamente ${ }^{30}$. Los intentos por lograr la paz en San Nicolás se dirigieron a aceptar todas las propuestas de los sublevados, quienes pidieron: la entrega de los títulos legales o ilegales de los hacendados; vivir «libremente» en las tierras arrendadas, sin «reclamo alguno sobre ellas» del dueño; y la suspensión de las contribuciones y de las obvenciones parroquiales a los «absolutamente pobres». El tratado fue aceptado en primera instancia por el jefe del cantón, pero no por los propietarios del lugar.

Cuando todo parecía arreglarse, al menos entre el gobierno federal y los rebeldes, un tercer movimiento violento acontecía. Los líderes no surgieron de las estructuras políticas indias o de los arrendatarios afectados por los excesos de los terratenientes. Ahora, los planes, peticiones y quejas tenían otras características y los líderes pertenecían a otros sectores socio-económicos. El 30 de diciembre de 1847, el subprefecto del partido de Chicontepec, Juan Llorente, y el capitán de la guardia nacional de Yanhuatlán, Eduardo Herrera, proclamaron el plan de Amatlán. Éste desconocía cualquier autoridad del gobierno local y estatal, declarando que el pueblo elegiría a sus representantes; prohibía todo cobro de renta de tierras, consideradas ahora comunales, o el pago de la «costumbre» y de obvenciones parroquiales a los curas. Una vez que los pueblos de los departamentos eligieran un jefe político, se haría la guerra al «enemigo invasor», en este caso, a los norteamericanos. El plan reflejaba la situación de un campesinado que había perdido sus tierras y pagaba renta al hacendado de San Benito, quien justamente era quien se levantaba ahora en armas.

30 El 29 de abril de 1859, los pobladores de Amatlán, Tancoco y San Antonio lograron concluir la compra de la hacienda de San Benito. AGN, Nacionalización y Desamortización de bienes, exp. 569-92/133. 
Los problemas se acentuaron en las Huastecas el primer día del año de 1848: el comandante militar de Huejutla se presentaba en Tantoyuca para solucionar el problema de las elecciones del ayuntamiento. Uno de los alcaldes electos no había logrado el goce de sus derechos, según Ramón Núñez, jefe político del departamento de Tampico que residía en Tantoyuca. La población se encontraba dividida entre los que sostenían la autoridad del jefe político y el sector que pretendía llevar adelante las nuevas elecciones. Este grupo, encabezado por Juan Llorente era el más numeroso y contaba con el apoyo de los soldados de la guarnición. La situación empeoró cuando el comandante militar suspendió las reuniones del ayuntamiento hasta la aclaración de los hechos. Como respuesta a la forma en que actuaba el comandante, el grupo inconforme lanzó el plan de Tantoyuca. Éste fue promulgado con características más políticas, ya que Llorente había logrado atraer al campesinado por medio del plan de Amatlán. Así, con los dos planes, Llorente cubría las expectativas de los dos grupos que lo apoyaban, por un lado, el campesinado y, por el otro, un fuerte sector de la elite huasteca.

El plan de Tantoyuca del 7 de enero de 1848 invitaba a la defensa del país, declaraba que los terrenos serían comunales; prohibía el cobro de la renta a los arrendatarios anteriores y futuros; designaba al jefe del pronunciamiento responsable de nombrar a los magistrados y empleados civiles; y eliminaba las contribuciones directas, alcabalas, así como el estanco del tabaco y el papel sellado. La única forma de financiar la administración sería por medio de los impuestos que los pobladores pagarían al municipio. Así, el plan estaba más ligado a los intereses comerciales y políticos de los líderes, que a los de los campesinos que apoyaban los planes. Es posible que la promesa de convertir las propiedades en comunes, así como la abolición de la renta y de algunas trabas a los productos comerciales, atrajera a muchos campesinos, pero su objetivo central no era tanto ése como el control de la maquinaria política de la región, razón por la que Llorente se reservaba el nombramiento de las autoridades civiles y volvía a proponer la creación de un estado huasteco, como ya se había hecho desde 1823.

Mientras se exponían los planes de Amatlán y Tantoyuca, el ayuntamiento de Tancanhuitz (San Luis Potosí), junto con 27 ciudadanos, lanzó el plan de Tancanhuitz (fechado «oficialmente» el 3 de febrero de 1848, aunque ya se sabía de él en enero). Con él se llamaba a la defensa del país contra los invasores y se desconocía al gobernador por su enfrentamiento con el Congreso estatal y al prefecto. Asimismo, se restringía el estanco del tabaco por ser «sólo de derecho de existencia faltando en general el surtido de labrados», y se suprimían las aduanas y las alcabalas por las condiciones que imperaban en el país. Inmediatamente casi todos los ayuntamientos secundaron el Plan, con excep- 
ción del pueblo de San Antonio, ya que ahí estaba residiendo el prefecto. En un informe a las autoridades potosinas mencionaba que tanto el subprefecto J. Miguel Altamirano como Manuel Fernández Barberena encabezaban la rebeldía en contra de la autoridad. Sin embargo, el gobierno de San Luis Potosí realizó una lectura diferente de los acontecimientos al considerar que en el Departamento de Tancanhuitz «se levanta el pueblo exigiendo imperiosamente la concesión de terrenos ${ }^{31}$. Quizá la idea del gobernador partía del acta de adhesión de Tamazunchale, que contenía tres artículos con características agrarias, aspecto que no consideraba el Plan de Tancanhuitz.

El prefecto y sus aliados tuvieron que retirarse de sus diversos puestos cuando los ayuntamientos huastecos coincidieron en que las autoridades potosinas y el prefecto se habían separado del «sendero de la ley». Sin embargo, los derrotados volvieron a la carga a fines de 1848 e impugnaron las elecciones para el ayuntamiento de Villa de Valles con el argumento de que sus antiguos adversarios habían manipulado las elecciones. Aun cuando el gobierno de San Luis Potosí no tomó en cuenta sus quejas, no se desanimaron, ya que tenían un as bajo la manga: al rebelde serrano Eleuterio Quiroz. En mayo de 1849, éste le dijo a Manuel Verástegui (pariente de un importante hacendado de Rioverde, San Luis Potosí) que refrendara los acuerdos que se estaban negociando con el general Anastasio Bustamante, con el fin de incluir «en los tratados lo que quieran los de Tancanhuitz y lo que más Ud. quiera» ${ }^{32}$.

Los planes de Amatlán, Tantoyuca y Tancanhuitz resultaron de la confrontación entre miembros de los grupos de poder regional que trataban de controlar diversos espacios en torno a Chicontepec, Villa de Valles, Tancanhuitz, Tantoyuca, Tampico y Tuxpan. Estos grupos se definían a sí mismos en función de sus intereses. En el caso de Tantoyuca, los sectores eran comerciantes, el de Llorente se remontaba a finales del siglo XVIII, alcanzando su mayor fuerza durante la guerra insurgente, y el de Ramón Núñez, a principios del siglo XIX. Núñez centraba toda su actividad hacia la Huasteca potosina y el puerto de Tampico, mientras que Llorente hacia Tuxpan, Chicontepec y Villa de Valles, por lo que la presencia de Núñez en Tantoyuca obstaculizaba y rivalizaba su expansión hacia otros mercados.

A la par de la sublevación bajo la bandera del plan de Tantoyuca, comenzaron a llegar informes al gobierno central de la posible unión de Manuel Herrera, Juan Llorente y Cristóbal Andrade, prefecto de Huejutla, con el general Esteban Barbero, que secundaba el plan monarquista de San Luis con las pro-

31 AHESLP, Secretaría General de Gobierno, leg. 1848.9.

32 Ibidem, legs. 1848.2; 1847.26. 
puestas de Paredes y Arrillaga en contra del gobierno nacional. En febrero y marzo se consideró, nuevamente, la posibilidad de que los sublevados tuvieran negociaciones y comercio con los norteamericanos, ya que San Nicolás había ofrecido ponerse bajo la protección de la bandera de los Estados Unidos. Asimismo, la inquietud de las movilizaciones en Veracruz se comenzó a sentir cada vez más en el lado potosino de las Huastecas. El 28 de enero de 1848, el presidente municipal, Manuel Mayorga, y los vocales del ayuntamiento de Tamazunchale (Huasteca potosina) discutieron con los caudillos indígenas de cada una de las fracciones y de la cabecera ${ }^{33}$ y con los «viejos generales» el Plan de San Nicolás ${ }^{34}$. Aceptaron éste en su totalidad, salvo con la modificación del artículo quinto, referente a que se tomaban en posesión los terrenos que pertenecían a los pueblos del municipio por los que se había litigado varios años atrás. De esta manera el tema de las tierras sirvió como un elemento detonante y aglutinador, cuya fuerza se canalizaría en contra del grupo rival. No solamente el ayuntamiento y los vecinos de Tamazunchale se adhirieron a la rebelión de San Nicolás, sino que apoyaron un día después el Plan de Tancanhuitz, insistiendo en el respeto a las propiedades y a las personas, así como en facultar al ayuntamiento el arreglo con el cura de la tasa de las obvenciones. $\mathrm{Su}$ mayor empeño fue que en «los litigios de tierras entre los dueños de haciendas colindantes con esta villa y los indígenas se cortaran presentando sus documentos y títulos ambas partes a la autoridad competente, para que ésta de la debida posesión a la parte que las pida, cuyo auto se expresara frente a dicha autoridad $»^{35}$. De esta manera trataban de solucionar parte de los conflictos, así como contar con el apoyo indígena. Sin embargo, no se iba a llegar a una tan pronta solución, ya que aun cuando el ayuntamiento de Tamazunchale aceptó en primera instancia el plan promulgado en Veracruz (Plan de San Nicolás), un mes después se negó a secundarlo. Este hecho ocasionó que dos de los barrios

33 Las fracciones eran Chapulhuacanito, Huesco, Matlapa, San Francisco, La Bandera, Santiago, Mecatlán y Picula. Por medio del decretó núm. 45 del 23 de septiembre de 1848 Huesco se agregó a San Martín. La Época. Periódico Oficial del estado de San Luis Potosí, 28 de septiembre y 10 de octubre de 1848 .

34 No sabemos con exactitud a que rebelión se referían, ya que como hemos visto el «Plan de Amatlán» fue promulgado el 30 de diciembre de 1847 y en los primeros días de enero de 1848 se proclamó el «Plan de Tantoyuca», ambos en Veracruz y en los dos casos el pueblo de San Nicolás estuvo involucrado. En varias ocasiones las autoridades potosinas locales hablaban del Plan de Barlovento, Plan de Ozuluama o Plan de San Nicolás. Se consideraba que el Plan de San Nicolás se publicó el 20 de diciembre de 1847; el acta de adhesión del ayuntamiento de Tamazunchale del 28 de enero de 1848 menciona el 16 de enero como la fecha de promulgación.

35 AHESLP, Secretaría General de Gobierno, leg. 1848.13. 
que pertenecían a la cabecera municipal, además de varios «vecinos» de la cabecera, presionaran para que el ayuntamiento se retractara de su negativa. Pascual Antonio («como capitán por nombramiento que adquieren en la nombrada antiguamente comunidad») lideró la petición de que las autoridades municipales les entregaran las tierras que solicitaban. En este momento Francisco Peña y su hermano asumieron la dirección de la rebelión «popular», poniendo en entredicho el papel del órgano de gobierno. De esta manera, lo que era un conflicto de intereses entre los diversos grupos de poder de la Huasteca potosina, se tornó en una manifestación violenta encabezada por antiguos insurgentes y federalistas que enarbolaron la bandera de la recuperación de tierras, con el fin de ver cubiertas las expectativas de sus seguidores y contar con aliados.

La violencia que se dio en Tamazunchale sirvió para realizar un «ajuste de cuentas» entre los miembros de los grupos de poder. Ello lo demuestra la muerte de uno de los hijos de Rivera, la persecución que sufrió éste por parte de los indígenas, y el hecho de que «casualmente» las tierras que estaban en litigio y solicitaban los barrios indígenas pertenecieran a haciendas de su propiedad como Huatepango y Tequesquite, a la hacienda de la Isla de Antonio de los Santos, y a los terrenos de Tenescalco de Agustín Villaverde, también opositores de Peña. Los enfrentamientos en la Huasteca potosina se dieron de manera breve y con pocas bajas, pero sirvieron para incrementar la animadversión entre los actores en conflicto. El ataque de los rebeldes a La Garita, propiedad de los Rivera, y al rancho Achichico, donde mataron a Felipe Rivera y robaron las mulas, los caballos, el maíz y la ropa del dueño, no solo causó indignación en los Rivera, sino que repercutió en los propios indígenas. Rivera atacó a Huesco, apresando al capitán de los indios y remitiéndolo, junto con algunos seguidores del «Plan de San Nicolás», amarrados a San Martín, donde los recibió su hijo Ramón, quien los envío a la cárcel del pueblo. Sin embargo, los conflictos de intereses o el cobro de deudas personales pendientes no solamente se daban entre los miembros de los grupos de poder. El grueso de las fuerzas sublevadas estaba integrado por indígenas, algunos rancheros y artesanos mestizos. Los primeros procedían de los barrios de La Bandera y San Francisco, así como de Tamazunchale y otras pequeñas rancherías cercanas, mientras que los segundos provenían de Xilitla y de los alrededores de Tamazunchale. Todos los rebeldes prisioneros insistieron en que fueron los indios los que invitaron a Pablo Castellón a que «bajara» con los pames de la Sierra de Xilitla para apoyarlos a no pagar las alcabalas y las contribuciones ${ }^{36}$. Los de

36 El 24 de febrero de 1848, a la mitad de la sublevación, el administrador de alcabalas de Tancanhuitz, solicitaba una pequeña fuerza con el fin de cobrar las alcabalas y contribuciones, principalmente de los indígenas de Tamazunchale que debían 400 pesos de igualas; por otra 
San Francisco y La Bandera, apoyados por los pames, atacaron y persiguieron al gobernador y al auxiliar de ambas congregaciones, tratando de matarlos (como sucedió con un par de sirvientes del gobernador) y liberando a los indios que habían sido remitidos a la cárcel por diversas faltas.

Tras su adhesión al plan de San Nicolás, los indígenas exigieron con vehemencia la restitución de las tierras. Frente a la petición tumultuosa y con las armas por delante, el regidor y el procurador síndico de Tamazunchale opusieron una leve resistencia junto con el gobernador indio, ya que consideraron que no se las iban a reconocer como propias tan pronto se presentaran las fuerzas del gobierno. Sin embargo, los funcionarios municipales fueron compelidos por Francisco Peña a llevar a cabo los acuerdos, debido a que con ello se apagaría «la lumbre que estaba encendida, y que si no el mismo, se echaría sobre el pueblo». De esta manera, a finales de febrero de 1848, Pedro Cabrera como regidor y «alcalde que funcionó en la sublevación» entregó las tierras (Achichipe, el Encino Solo, Cosajapa y el Llano de Pastle) a los indígenas de Tamazunchale, Matlapa y Axtla. En el caso de los primeros se les dio algunos de los terrenos de la hacienda de Huatepango y en el de los segundos las tierras litigadas con la hacienda la Isla. Los nahuas se retiraron del conflicto una vez vieron cumplidas sus expectativas de obtener tierras y la «venganza» sobre algunas de sus autoridades, pero no así los pames que continuaron participando. La rebelión de Tamazunchale duró casi cincuenta días y terminó con la presencia de fuerzas de la guardia nacional de Tancanhuitz y Villa del Maíz encabezadas por el comandante que había proclamado el Plan de Tancanhuitz.

\section{UNA TERCERA FASE EN LA VIOLENCIA}

La impotencia cundía entre los mestizos y blancos de las cabeceras políticas huastecas, sobre todo por el avance de los indígenas hacia la actual Huasteca hidalguense. La desesperación ocasionó que algunos sectores políticos de las Huastecas solicitaran ayuda a las tropas norteamericanas para pacificar la región, sobre todo porque consideraban que el gobierno mexicano hacia poco para conservar sus vidas y bienes ${ }^{37}$. Así, el comandante militar de Huejutla avisó que el prefecto de ese pueblo, Cristóbal Andrade, había solicitado ayuda

parte, consideraba que con esa fuerza se contendría el «torrente del escandaloso contrabando que se hace al abrigo de tantos pronunciamientos sin recato». AHESLP, Secretaría General de Gobierno, leg. 1848.12.

37 Ducey, 2004, considera que los campesinos de las Huastecas tuvieron en el fondo un espíritu nacionalista, ya que sus intereses se vieron afectados por la invasión extranjera. 
a las tropas norteamericanas estacionadas en Tampico. La acusación fue cierta, ya que tiempo después Andrade escribía una extensa justificación de su acto. En ella expresó el pensamiento que tenían las autoridades mexicanas y en general todo aquel que se sentía «blanco» o no indio y sólo tenían una presencia significativa en las cabeceras políticas de las Huastecas. Andrade consideraba que $«[\ldots]$ La guerra de muerte y exterminio que han declarado los sublevados a la clase blanca y a los acomodados, la ramificación que por la revolución tiene en todos los pueblos, pues la mayoría de sus habitantes se compone de indígenas agrestes [...] han llamado seriamente mi atención». También abundaba en la posible extensión de los sucesos de Sierra Gorda y Yucatán «al resto de la república, que fácilmente podría ser envuelta, transmitiéndose esas ideas al sur y a todo el valle de México» ${ }^{38}$. Frente al descrédito de las autoridades locales y a la poca actividad desplegada por el ejército, el gobernador del Estado de México ordenó el 15 de julio de 1848 que el diputado José M. ${ }^{a}$ Verdiguel fuera a negociar con los pueblos sublevados. Las siete instrucciones que se le dieron iban dirigidas a investigar si eran ciertas las acusaciones en contra del prefecto de Huejutla. Asimismo, el enviado tendría que intentar negociar la paz con los sublevados, evitando que los líderes volvieran a residir en los pueblos rebeldes (instrucción tres); además, procuraría que «los pueblos queden con su fundo legal, y demás tierras comunes con arreglo de las leyes $»^{39}$. Las sanciones en contra de Andrade nunca se llevaron a cabo, ya que un año después el gobernador del estado de México mencionó en el congreso estatal que las acusaciones hechas habían sido «falsas».

A mediados de 1848 los funcionarios locales coincidían en un punto importante, la rebelión había dejado de tener un número considerable de indígenas y se conformaba de mestizos, negros, mulatos y blancos, por lo que los que estaban ahora en rebeldía eran arrendatarios y rancheros, no tanto miembros de los pueblos. La protesta de estos sectores se debió al cobro imprudente del impuesto de capitación, que aumentaba la presión fiscal y ocasionaba la «pobreza» de los campesinos. Para esas fechas, el movimiento dejó de lado los intereses de los miembros de los grupos de poder regional que los había convocado. La presencia de rebeldes en la Huasteca hidalguense y al sur de

\footnotetext{
38 Expresiones semejantes plasmaron los hacendados del Estado de México en su conflicto en el gobernador Arizcorreta en 1848. Véase Escobar Ohmstede, 1999: 139-146. Por la supuesta traición de Cristóbal Andrade los municipios de Metztitlán y Zacualtipan lo desconocieron como jefe político, separándose del distrito. AHSDN, exp. XI/481.3/2772, fs. 56-57.

39 AGN, Gobernación, caja 357, exp. 2, s/s, fs. 57-59. Posteriormente los gobiernos de Puebla y Veracruz nombraron a Verdiguel como su comisionado para negociar con los rebeldes.
} 
Amatlán (Huasteca veracruzana) permite pensar que el movimiento ya no fue controlado por Llorente, Andrade y Herrera. Posiblemente los dirigentes habían conseguido las metas propuestas, por lo que se convirtieron en represores. Así, surgieron nuevos líderes como Hilario Galván y Pedro Hernández. El primero concentró sus actividades en la Huasteca veracruzana, mientras que el segundo en la Huasteca hidalguense. A partir de esta nueva dirigencia el movimiento tuvo otras características. En una proclama de Galván fechada el 5 de junio de 1848, mencionaba que el asunto que defendían con las armas ya no era político como a principios de año, sino en contra de los hacendados que en contubernio con las autoridades civiles y militares explotaban y asesinaban a los campesinos, esto es, se regresaba a la primera fase de la violencia, donde las solicitudes de los pueblos giraban en torno a la tierra y los impuestos civiles y eclesiásticos. Galván denunció la política represiva del ejército de «tierra arrasada» en los pueblos y rancherías rebeldes, así como en los campos con siembras $^{40}$. Hasta ese momento se encontraban levantados casi dos mil hombres, de los cuales ochocientos se ubicaban cerca de Huejutla, mil por Tamiahua y Temapache, y como trescientos por Ozuluama. Las partidas eran de doscientos a cuatrocientos hombres, las que a su vez se subdividían en grupos de no más de cincuenta individuos, lo que les permitía atacar rápidamente pueblos y haciendas. La movilidad y guerra de guerrillas que desarrollaban los rebeldes les permitía embestir los pueblos de Temapache, Ozuluama, Chontla, Huautla y Tantima este último en represalia de los ataques del ejército, e incendiar varias haciendas como las de Chila, Nopal y San Sebastián ${ }^{41}$.

El gobierno central se encontraba en un dilema, por un lado la rebelión del general Paredes y Arrillaga parecía tomar fuerza gracias a su alianza con los rebeldes de Sierra Gorda, alzamiento que iba en contra de los tratados de paz con los Estados Unidos de América y, por el otro, los rebeldes de las Huastecas pretendían unirse a los levantados de la Sierra Gorda. El prefecto de Huejutla consideró que la unión de los rebeldes huastecos con los serranos traería como consecuencia la «revolución de castas que será difícil de contener y tan

40 Un año después los indígenas decían que: «Cuando nuestros ojos se dirigen a las montañas que habitamos y lo vemos arrasado por el incendio, nuestros ojos se bañan de lágrimas». AGN, Gobernación, caja 383, exp. 13, s/s.

41 Las autoridades consideraban a los rebeldes como «anarquistas», AGN, Gobernación, caja 357, exp. 2, fs. 106-109; El Monitor Republicano, 11 de junio de 1848. El tipo de guerrillas no difiere mucho de lo realizado en otras partes del país, así como de América Latina. Véase para Colombia Ortiz, 2004: 101-158. Para Perú, Walker, 1999: 267-276. Jacobsen y Díez Hurtado, 2002: 59-67. Mallon, 2003. Para México, Thomson y LaFrance, 1999. Para Venezuela, Blanchard, 1998: 93-118. 
horrorosa como lo es el modo encarnecido con que ya se ha manifestado y ramificado por toda la República» ${ }^{42}$.

\section{UNA CUARTA FASE DE LA VIOLENCIA}

En 1849 se recibían noticias del ingreso de los «serranos» encabezados por Eleuterio Quiroz a la Huasteca potosina tras la derrota infringida a las fuerzas del prefecto Altamirano. Los rebeldes avanzaron a través de Xilitla, pasando por Huehuetlán, San Antonio, Aquismón, Tancanhuitz y Valles. La ruta tocaba pueblos importantes de la Huasteca potosina, dejando a su paso desolación, robos y muertes. Sin embargo, en octubre de 1849, el alcalde constitucional de Landa (Querétaro) avisaba a las prefecturas de Rioverde y Tancanhuitz que Eleuterio Quiroz había sido capturado por su antiguo aliado, Tomás Mejía, con lo que se consideraba que la rebelión había llegado a su fin; aun cuando algunas partidas seguían rondando varios pueblos de la Sierra Gorda y del sur de San Luis Potosí.

Pero, ¿por qué Quiroz había abandonado la Sierra Gorda y Rioverde donde no solamente contaba con hombres y bastimentos, sino también con aliados importantes como Manuel Verástegui? A partir de las quejas de varios vecinos del departamento y de la correspondencia del prefecto de Tancanhuitz la incursión a la Huasteca se debió a la invitación que le hicieron Gabriel, Manuel y Pedro Castellanos, así como Santiago Andreo y Tomás González, para destituir a las personas que ocupaban los puestos militares y civiles. Éstos eran los Altamirano y los Fernández Barberena, sus «antiguos» adversarios de 1847 y 1848. Los vecinos que se quejaron por el accionar de los serranos, acusaban directamente a los Castellano con calificativos diversos. Sin duda, las diversas cartas que llegaron a manos del gobernador potosino, canalizadas por el prefecto Altamirano, mostraban una parte importante del conflicto, la lucha entre los diversos grupos de poder huastecos, así como la actitud de los serranos hacia ciertos «notables».

Los Castellano en alianza con los serranos de Quiroz pretendieron recuperar los puestos y su papel dentro de la región a un alto costo. No sabemos con certeza que sucedió en los pueblos que fueron ocupando los rebeldes, pero si tomamos como un ejemplo lo acontecido en San Antonio, podemos esbozar el panorama que se vivió en el segundo semestre de 1849. A la entrada de los serranos a San Antonio, en mayo, éstos se centraron en ubicar a las autoridades

\footnotetext{
42 AHSDN, exp. XI/481.3/2835, f. 68.
} 
de la localidad, con el fin de saquear sus casas y. en muchos casos, asesinarlos, como ocurrió con el juez de lo criminal, el receptor de rentas y el alcalde. Respecto a ellos, sus viudas declararon que la muerte de sus esposos había carecido de sentido ya que éstos se habían rendido a las puertas de sus casas. Sin embargo, los rebeldes no solamente ejecutaron y robaron a los funcionarios, sino también buscaron al preceptor (maestro de escuela) y a los comerciantes que habían huido de Huehuetlán y Tancanhuitz. El monto de lo robado alcanzó casi los trece mil pesos, cantidad nada desdeñable que los afectados solicitaron más tarde al gobierno estatal que les fuera pagada, así como que se castigase a los Castellano y González por los asesinatos.

La incursión de los hombres de Quiroz no logró el efecto deseado cuando comenzaron a regresar a Xilitla en septiembre. Al contrario, sus aliados huastecos no solamente fueron censurados por las diversas instancias políticas y sociales, sino también perseguidos y sus bienes embargados. Algunos, como Tomás González, buscaron refugio en Rioverde, otros fueron constantemente vigilados por los jueces, subprefectos y el prefecto con el fin de evitar cualquier otra posible sublevación. Esto último no funcionó porque un año después, varios «subalternos» que habían luchado al lado de Francisco Peña se levantaron en armas en Tamazunchale en contra del prefecto Altamirano, quien había aprendido bien la lección anterior. En este caso la rebelión fue rápidamente sofocada por los aliados de Altamirano.

Frente a estos hechos, se presentaba la escasez de hombres para evitar la unión de los rebeldes. El general Arista, como Ministro de Guerra, manifestaba la imposibilidad de mandar tropas profesionales a las Huastecas por la necesidad de derrotar a Paredes, en cambio sugería que el gobernador del Estado de México enviase milicias de Tulancingo a Huejutla. Con la derrota de Paredes por el general Anastasio Bustamante se pudieron enviar tropas a Huejutla. A la par de la acción represora realizada por el ejército y las milicias locales, el gobierno mexicano solicitó la ayuda de la Iglesia para terminar con la violencia colectiva. Las autoridades eclesiásticas aceptaron rápidamente el papel de pacificadores. Enviaron pastorales, edictos y circulares a todos los curas de las zonas levantadas para que por medio de la predicación los indígenas volvieran a la $\mathrm{paz}^{43}$, siendo éste uno de los pocos momentos en que la Iglesia apareció como mediadora en el conflicto huasteco.

43 AGN, Papeles de Bienes Nacionales, leg. 200, exp. 14. El ofrecimiento del cabildo eclesiástico metropolitano de la ciudad de México no fue fortuito. El cabildo consideró que gracias al apoyo que estaban brindando, el gobierno mexicano debería considerar su política respecto a la tolerancia de cultos, hecho que desde la perspectiva eclesiástica provocaba poco control en las zonas rurales. 
La represión, el cansancio o la falta de bastimentos ocasionaron que muchos rebeldes solicitaran el indulto, como fue el caso de los pertenecientes a las rancherías de Ozuluama, Chontla, Tantima, Tepecintla y San Nicolás. El 1 de agosto de 1848 el presidente de la República otorgó el indulto general a los sublevados de la Sierra Gorda y de los distritos de Huejutla y Huauchinango. El bando del coronel Manuel Montero, comandante principal de la línea militar de Huejutla, dijo que se otorgaba el indulto: «en atención a que los indígenas han sido reducidos y arrastrados a la revolución sin de que su parte haya tenido más culpabilidad de prestarse incautamente a servir de instrumento de los anarquistas ${ }^{4}{ }^{4}$. Sin embargo, los acuerdos firmados y los indultos de las autoridades civiles en las Huastecas no fueron respetados ${ }^{45}$. El rumor de la presencia de Velázquez reavivó la rebelión en los primeros meses de 1849. La noticia ocasionó que los campesinos atacaran nuevamente Ozuluama quemando las casas de las autoridades civiles y de algunos hacendados. El gobierno organizó a algunas de las milicias locales formadas por hombres provenientes de las propiedades privadas. Con ellas atacaron Ozuluama, que fue tomada «a sangre y fuego»y y dispersados de esta manera a los rebeldes.

¿Pero qué pasó después de las rebeliones? Un año más tarde había preocupación por otra rebelión, las autoridades recibían cartas sobre posibles conspiradores y revueltas. El problema sobre la legitimidad de la posesión de la tierra continuaba. A esta cuestión, se unía el que los indígenas comenzasen a solicitar permiso para reedificar el pueblo de San Nicolás, hecho al que se negaban las autoridades de Ozuluama, Tantima y Chontla porque consideraban que era mejor que los indígenas vivieran dispersos en el departamento de Tampico. El temor a que los indígenas se levantaran en el futuro fue una constante en el pensamiento de los blancos y mestizos, ya que frente a cualquier reunión numerosa de indígenas, las autoridades informaban de posibles «sublevaciones de castas» ${ }^{46}$. Para fortuna de los «blancos», los «proletarios» no volvieron a organizar contingentes armados que luchasen por la recuperación de la propiedad, la disminución de las rentas de los arrendamientos, la eliminación de los servicios personales o la «transparencia» en las elecciones municipales. En la primera mitad del siglo XIX sólo tuvieron lugar estas

44 Recorte del periódico El Noticioso del 19 de agosto de 1848. El Monitor Republicano del 11 de junio de 1848 consideraba que habían sido instrumento de los monarquistas.

45 A principios de 1849 el ministro de Relaciones Interiores ordenó a los gobernadores de México y Veracruz que hicieran respetar los indultos concedidos a los rebeldes. AGN, Gobernación, caja 349 , exp. 16 , s/s.

46 El prefecto de Huejutla consideró en 1853 que los indígenas iban a apoyar el Plan de Guadalajara. AGN, Gobernación, caja 427, exp. 3, s/s, 3 fs. 
manifestaciones violentas, lo que sucedió en la segunda mitad aún ha sido poco estudiado.

\section{CONSIDERACIONES FINALES}

Como pudimos apreciar, la violencia en las Huastecas tuvo puntos comunes que sirvieron como detonantes. Las elecciones en los ayuntamientos y su control por sectores de los grupos de poder supusieron una participación activa de los indígenas, aunque debemos considerar que, tanto dentro de los movimientos como en la elección de los funcionarios municipales, ésta fue protagonizada fundamentalmente por los «notables». Los conflictos políticos nacionales ocasionaron que las sociedades rurales en su conjunto se vieran inmiscuidas en este tipo de luchas. No podemos dudar acerca de que las reivindicaciones campesinas estaban inmersas en las políticas en una primera fase, situación que posteriormente cambió cuando las «masas» comenzaron, probablemente, a perder el contacto con los líderes o cuando éstas deciden retomar las quejas iniciales. Este tipo de conflicto político social puede ser observado como un conflicto faccional en el sentido de que las facciones rurales son estructuralmente semejantes, es decir, representan similares configuraciones de grupos sociales.

Las reivindicaciones plasmadas en los planes de Amatlán, Tantoyuca y «San Nicolás» reflejaban necesidades de los sectores rurales concernientes a la suspensión de las obvenciones parroquiales, la reducción de las rentas de arrendamiento y la eliminación de algunos impuestos personales que afectaban directamente a la economía rural. La lucha por la tierra también estuvo presente en las quejas y planes campesinos. Es importante observar cómo los movimientos huastecos se desarrollaron en zonas en que la hacienda como forma de tenencia de la tierra estaba presente y se ligaba a un tipo de actividad ganadera que había ido desplazando a las actividades agrícolas de los habitantes de los pueblos. Este aspecto explica por qué en el caso de los levantamientos de Amatlán y Tantoyuca su radio de acción no fue más allá del espacio y la realidad conocida por los rebeldes. No hubo un levantamiento generalizado de los pueblos apoyando los planes políticos. Quizá sólo en la última fase de la rebelión, cuando ya no fueron los pueblos quienes participaban en el movimiento, sino partidas sin una pertenencia específica, podríamos hablar de una rebelión en las Huastecas, de manera más generalizada, básicamente por la movilidad que llegaron a tener los rebeldes.

Un aspecto más que se puede resaltar es que los movimientos tuvieron una composición socioeconómica heterogénea. En el aspecto social participaron 
indios, negros, blancos, mulatos y mestizos; mientras que en el económico existieron arrendatarios, rancheros y comuneros indígenas, situación que nos permitiría hablar, no de una «guerra de castas» cuya finalidad era la extinción del «blanco», sino de una violencia social dirigida en contra de la injusticia de las autoridades civiles y de los propietarios. Podríamos pensar en una composición multiétnica de los movimientos, lo cual es parcialmente cierto, pero también es importante mencionar que en algunas fases de las rebeliones la conformación social fue preponderantemente india, sin que ello impidiese que otros sectores socio-étnicos se unieran a la lucha en protesta por agravios sin solución, sobre todo si estamos considerando que desde la Colonia no existían pueblos que solamente estuviesen conformados por indígenas. Asimismo, en el análisis de la violencia rural presentado aparece constantemente la división interna de los pueblos de indios, ya que algunos disfrutaban de más bienes y poder que otros. En muchas ocasiones los conflictos tomaron la forma de rivalidad entre los pueblos sujetos y los ayuntamientos de los pueblos cabecera, en donde los indígenas querían participar, notándose que fueron los oficiales de las congregaciones, rancherías y sujetos, los que fungían como organizadores de las protestas campesinas.

Otro factor de tensión provino de fuera del pueblo en la forma de funcionarios gubernamentales, curas e impuestos. Los ataques contra estos últimos, como el caso de la alcabala, nos hacen pensar en la inconformidad de algunos sectores dedicados a abastecer las redes comerciales huastecas. En cuanto a lo sucedido con la retirada de los militares, se sabe poco o se ignora. Pero los propietarios todavía tenían que tratar con los mismos arrendatarios, rancheros o comuneros que se habían rebelado, y sobre todo, en muchos casos los rebeldes conservaban las armas que les habían facilitado los grupos beligerantes.

\section{BIBLIOGRAFÍA}

Birrichaga, Diana, «Luchas y defensa de los pueblos: el derecho al agua en el centro de México (1856-1868)», José Ronzón y Carmen Valdez (coords.), Formas de descontento y movimientos sociales, siglos XIX y XX, México, UNAM, 2005: 255-282.

Blanchard, Peter, «La agresividad de los esclavos en Venezuela y Argentina durante las guerras de independencia», Anthony McFarlane y Marianne Wiesebron (coords.), Violencia social y conflicto civil: América Latina, siglos XVIII-XIX, Holanda, AHILA, 1998: 93-118.

Blázquez, Carmen, Breve historia de Veracruz, México, El Colegio de México-Fondo de Cultura Económica, 2000. 
Corbett, Bárbara, «Comercio y violencia en la Huasteca potosina: el monopolio del tabaco, 1821-1846», Antonio Escobar Ohmstede y Luz Carregha (coords.), El siglo XIX en las Huastecas, México, CIESAS-El Colegio de San Luis, 2002: 235-268.

Ducey, Michael T., «Indios liberales y liberales indigenistas: ideología y poder en los municipios rurales de Veracruz, 1821-1890», Antonio Escobar Ohmstede y Luz Carregha (coords.), El siglo XIX en las Huastecas, México, CIESAS-El Colegio de San Luis, 2002: 111-136.

Ducey, Michael T., A Nation of Villages. Riot and Rebellion in the Mexican Huasteca, 1750-1850, Tucson, The University Arizona Press, 2004.

Escobar Ohmstede, Antonio, «Los ayuntamientos y los pueblos indios en la sierra huasteca: conflictos entre nuevos y viejos actores, 1821-1840», Leticia Reina (coord.), La reindianización de América, siglo XIX, México, Siglo XXI-CIESAS, 1997: 294-316.

Escobar Ohmstede, Antonio, De la costa a la sierra. Las Huastecas, 1750-1900, México, CIESAS-INI, 1998.

Escobar Ohmstede, Antonio, «Los pueblos indios en el siglo XIX: el caso del Estado de México», Mílada Bazant (coord.), 175 años de historia del Estado de México y perspectivas para el tercer milenio, México, El Colegio Mexiquense, 1999: 135-166.

Escobar Ohmstede, Antonio y Falcón, Romana (coords.), Los ejes de la disputa. Movimientos sociales y actores colectivos en América Latina, siglo XIX, Madrid, AHILA-Iberoamericana-Vervuert, 2002.

Escobar Ohmstede, Antonio, «Las dirigencias y sus seguidores, 1811-1816. La insurgencia en las Huastecas», Marta Terán y José Antonio Serrano Ortega (eds.), Las guerras de independencia en la América española, México, El Colegio de Michoacán-INAH-Universidad Michoacana de San Nicolás de Hidalgo, México, 2002: 217-235.

Escobar Ohmstede, Antonio y Fagoaga, Ricardo A., «Los componentes socio-étnicos y sus espacios en las Huastecas a través de los censos parroquiales, 1770-1780», Estudios de Cultura Maya, XXV (México, 2004): 219-256.

Escobar Ohmstede, Antonio, «"Vil venganza". Movimientos políticos-sociales en la Huasteca potosina, 1845-1851», José Alfredo Rangel y Carlos R. Ruiz Medrano (coords.), Discursos públicos, negociaciones y estrategias de lucha colectiva. Aportaciones al estudio de las movilizaciones sociales en México, siglos XVIII y XIX, México, AHESLP-El Colegio de San Luis, 2006: 81-122.

Falcón, Romana, México descalzo. Estrategias de sobrevivencia ante la modernización liberal, México, Plaza y Janés, 2002. 
Falcón, Romana Falcón (coord.), Culturas de pobreza y resistencia. Estudios de marginados, proscritos y descontentos en México, 1804-1910, México, El Colegio de México-Universidad Autónoma de Querétaro, 2005.

Guardino, Peter, Peasants, Politics, and the Formation of Mexico's National State. Guerrero, 1800-1857, Stanford, Stanford University Press, 1996.

Hart, John, «La guerra de los campesinos del suroeste mexicano en los años de 1840: Conflicto en una sociedad transicional», Friedrich Katz (comp.), Revuelta, rebelión y revolución, México, Ed. ERA, 1988, vol. I: 225-241.

Herrera, Octavio, Breve historia de Tamaulipas, México, Fondo de Cultura Económica-El Colegio de México, 1999.

Irurozqui, Marta, «Las buenas intenciones. Venta de tierras comunales en Bolivia, 1880-1899», Leticia Reina (coord.), La reindianización de América, siglo XIX, México, Siglo XXI-CIESAS, 1997: 29-52.

Jacobsen, Nils y Díez Hurtado, Alejandro, «Montoneras, la Comuna de Chalaco y la revolución de Piérola: la Sierra Piurana entre el clientelismo y la sociedad civil, 1868-1895», Antonio Escobar Ohmstede y Romana Falcón (coords.), Los ejes de la disputa. Movimientos sociales y actores colectivos en América Latina, siglo XIX, Madrid, AHILA-Iberoamericana-Vervuert, 2002: 57-131.

Kónig, Hans-Joachim, «Artesanos y soldados contra el proyecto modernizador liberal en Nueva Granada: el movimiento revolucionario del 17 de abril de 1854», Antonio Escobar Ohmstede, Romana Falcón y Raymond Buve (comps.), Pueblos, comunidades y municipios frente a los proyectos modernizadores en América Latina, siglo XIX, México-Holanda, El Colegio de San Luis-CEDLA, 2002: 207-224.

Knight, Alan, «Continuidades históricas en los movimientos sociales», Jane-Dale Lloyd y Laura Pérez (coords.), Paisajes rebeldes, México, Universidad Iberoamericana, 1995: 13-52.

Mallon, Florencia, Campesino y Nación. La construcción de México y Perú poscoloniales, México, CIESAS-El Colegio de Michoacán-El Colegio de San Luis, 2003.

McFarlane, Anthony, «Introduction: Social Violence and Civil WAR in Late Colonial and Early Independent Latin American», Anthony McFarlane y Marianne Wiesebron (coords.), Violencia social y conflicto civil: América Latina, siglos XVIII-XIX, Holanda, AHILA, 1998:7-38.

Monroy, María Isabel y Calvillo, Tomás, Breve historia de San Luis Potosí, México, Fondo de Cultura Económica-El Colegio de México, 1997.

Ortiz, Juan y Serrano, José Antonio (eds.), Ayuntamientos y liberalismo gaditano en México, México, El Colegio de Michoacán-Universidad Veracruzana, 2007.

Ortiz Mesa, Luis Javier, Fusiles y plegarias. Guerra de guerrillas en Cundinamarca, Boyacá y Santander, 1876-1877, Colombia, Universidad Nacional de Colombia, 2004. 
Quijada, Mónica, «Una Constitución singular. La carta gaditana en perspectiva comparada», Revista de Indias, LXVIII/242 (Madrid, 2008): 15-38.

Rangel, José Alfredo, «"Unos hombres tan embrutecidos”. Insurgencia, alternativas políticas y revuelta social en la Huasteca potosina, 1810-1813», José Alfredo Rangel y Carlos R. Ruiz Medrano (coords.), Discursos públicos, negociaciones y estrategias de lucha colectiva. Aportaciones al estudio de las movilizaciones sociales en México, siglos XVIII y XIX, México, El Colegio de San Luis-AHESLP, 2006: 47-80.

Reina, Leticia, «Las rebeliones indígenas y campesinas (período colonial y siglo XIX)», Carlos García Mora y Martín Villalobos (coords.), La antropología en México. Panorama histórico, México, INAH, 1988, vol. IV: 517-541.

Reina, Leticia, «Una mirada a diferentes formas de reconstrucción histórica de las rebeliones. Período colonial y siglo XIX», Jane-Dale Lloyd y Laura Pérez (coords.), Paisajes rebeldes, México, Universidad Iberoamericana, 1995: 3-76.

Thomson, Guy y Lafrance, David, Patriotism, Politics, and Popular Liberalism in Ninettenth-Century Mexico. Juan Francisco Lucas and the Puebla Sierra, EUA, Scholary Resources Inc, 1999.

Tutino, John, From insurrection to revolution in Mexico. Social basis of agrarian violence, 1750-1949, Princeton, Princeton University Press, 1986.

Tutino, John, «Cambio social agrario y rebelión campesina en el México decimonónico: el caso de Chalco», Friedrich Katz (comp.), Revuelta, rebelión y revolución, México, Ed. ERA, 1988, vol. I: 94-134.

Tutino, John, «Comunidad, independencia y nación: las participaciones populares en las historias de México, Guatemala y Perú», Leticia Reina (coord.), Los retos de la etnicidad en los estados-nación del siglo XXI, México, CIESAS-INI-Miguel Ángel Porrúa, 2000: 125-152.

Walker, Charles F., De Tupac Amaru a Gamarra. Cusco y la formación del Perú Republicano, 1780-1840, Cuzco, Centro de Estudios Regionales Andinos Bartolomé de Las Casas, 1999. 


\section{SOCIAL VIOLENCE IN MEXICO IN THE FIRST HALF} OF THE 19th CENTURY: THE CASE OF HUASTECAS

This article looks at the different phases of the violence in the Huasteca space social during the first half of the nineteenth century. It offers a careful analysis of each of the rebellions considering their causes as well as the participation of many groups involved. It analysis the role of Indians, mestizos and mulatoes living in the pueblos and private propieraties and even important members of the elites and finally identifies their alliances and mechanisms of patronage used by these groups.

Key words: Rebellion, Popular Groups, Constitution, México, Huastecas. 